\title{
Molecular switch based on a cucurbit[6]uril containing bistable [3]rotaxane $\dagger+$
}

\author{
Dönüs Tuncel, ${ }^{a}$ Özgür Özsar, ${ }^{b}$ H. Burak Tiftik ${ }^{a}$ and Bekir Salih ${ }^{b}$ \\ Received (in Cambridge, UK) 16th November 2006, Accepted 9th January 2007 \\ First published as an Advance Article on the web 25th January 2007 \\ DOI: $10.1039 / \mathrm{b} 616764 \mathrm{k}$
}

A bistable CB6-based [3]rotaxane with two recognition sites has been prepared very efficiently in a high yield synthesis through CB6 catalyzed 1,3-dipolar cycloaddition; this rotaxane behaves as a reversible molecular switch and exhibits conformational changes caused by the movement of rings under base, acid and heat stimuli from one location to the other.

Mechanically interlocked molecules assembled through host-guest chemistry, such as rotaxanes and catenanes, containing more than one recognition site are proving to have great potential for the construction of molecular switches and motors. In these systems, the ring of the molecule can shuttle under external stimulus (chemical, electrochemical or photochemical) from one location to others. ${ }^{1}$ In doing this, they convert chemical, electrochemical or photochemical energy into mechanical energy. To date, many elegantly designed rotaxanes and catenanes have been reported. ${ }^{2}$ When appropriately designed, bistable [3]rotaxanes in particular have great potential to act as stimuli-responsive artificial molecular muscles. However, there are only a few examples of rotaxanes which resemble linear artificial molecular muscles. ${ }^{3-5}$ In these systems, the expansion and contraction caused by the movements of the hosts from one recognition site to the other can be monitored via spectroscopic methods $\left({ }^{1} \mathrm{H}\right.$ NMR, UV-Vis and fluorescence), and cyclic voltammetry.

Cucurbit[6]uril (CB6) and its homologues are among the hosts, which can be used in the preparation of rotaxanes. Cucurbituril is prepared from the acid condensation of glycoluril and formaldehyde; it has a hydrophobic cavity, along with two matching hydrophilic carbonyl portals. ${ }^{6-8}$ Owing to these structural features, CB6 binds well with protonated mono- and di-aminoalkanes mainly through ion-dipole interactions and the hydrophobic effect. Moreover, CB6 has been shown to catalyze 1,3-dipolar cycloaddition between properly functionalized alkyne and azide groups to yield 1,4-disubstituted triazoles. A number of rotaxanes and polyrotaxanes have been designed and synthesized by using the catalytic effect of CB6. ${ }^{9-12}$

There are a number of examples of CB6-based bistable [2]rotaxanes which behave as molecular switches. ${ }^{13}$ However, to the best of our knowledge, there is no example of a CB-based bistable [3]rotaxane mimicking the behaviour of artificial

${ }^{a}$ Department of Chemistry, Bilkent University, 06800, Ankara, Turkey. E-mail:dtuncel@fen.bilkent.edu.tr; Fax: (+90) 3122664579

${ }^{b}$ Department of Chemistry, Hacettepe University, 06580, Ankara,

Turkey

$\uparrow$ Dedicated to Professor Mary McPartlin.

* Electronic supplementary information (ESI) available: Synthesis and characterization of [3]rotaxane and ${ }^{1} \mathrm{H}$ NMR spectra of switching experiment (Fig. 3, enlarged). See DOI: 10.1039/b616764k

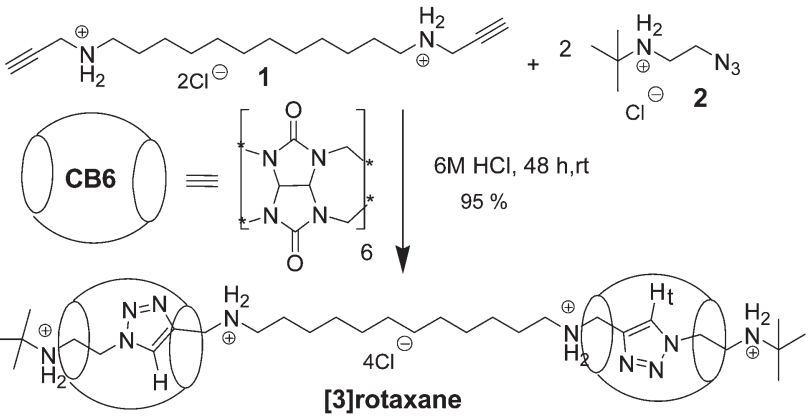

Scheme 1 Synthesis of CB6-based [3]rotaxane.

molecular muscles. Here, we report the design, synthesis and the reversible switching processes of a CB6 based [3]rotaxane. This rotaxane is prepared very efficiently by CB6-catalyzed 1,3-dipolar cycloaddition in a high yield; it is composed of two CB6s and a dumbbell with two recognition sites, namely diaminotriazole and dodecamethylene, a flexible spacer, which is long enough to accommodate more than one CB6. The movement of CB6s which can be triggered by base, acid and heat causes a large conformation change of this rotaxane. This has been investigated by ${ }^{1} \mathrm{H}$ NMR spectroscopy.

[3]Rotaxane was synthesized according to Scheme 1 by following the procedures described in the literature for the synthesis of similar compounds. ${ }^{11,12}$ It was fully characterized by spectroscopic techniques $\left({ }^{1} \mathrm{H},{ }^{13} \mathrm{C}\right.$ NMR and FT-IR), and elemental analysis.

Matrix assisted laser desorption/absorption mass spectrometry (MALDI-tof-MS) also confirmed the formation of [3]rotaxane (Fig. 1). The small peaks at $m / z 1559$ and 1637 are due to the

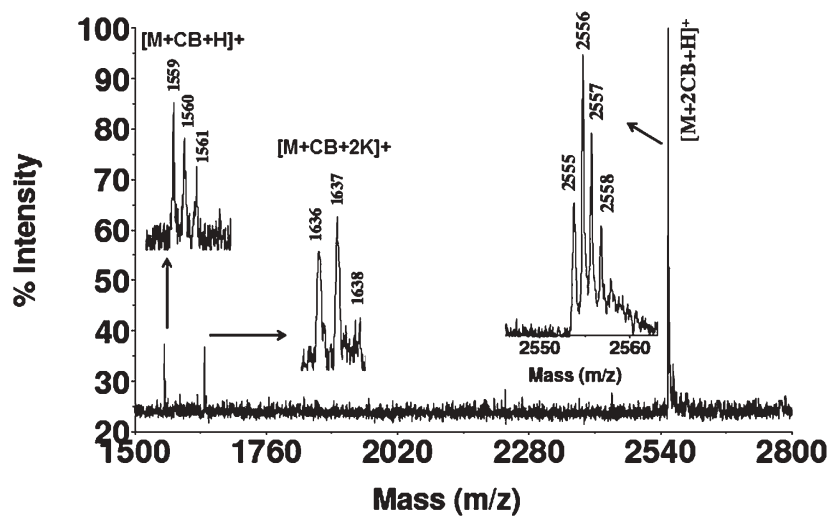

Fig. 1 Positive ion MALDI-tof-MS spectrum of [3]rotaxane in THAP, (2,4,6-trihydroxyacetophenone); $\mathrm{M}$ = dumbbell. 
(a)
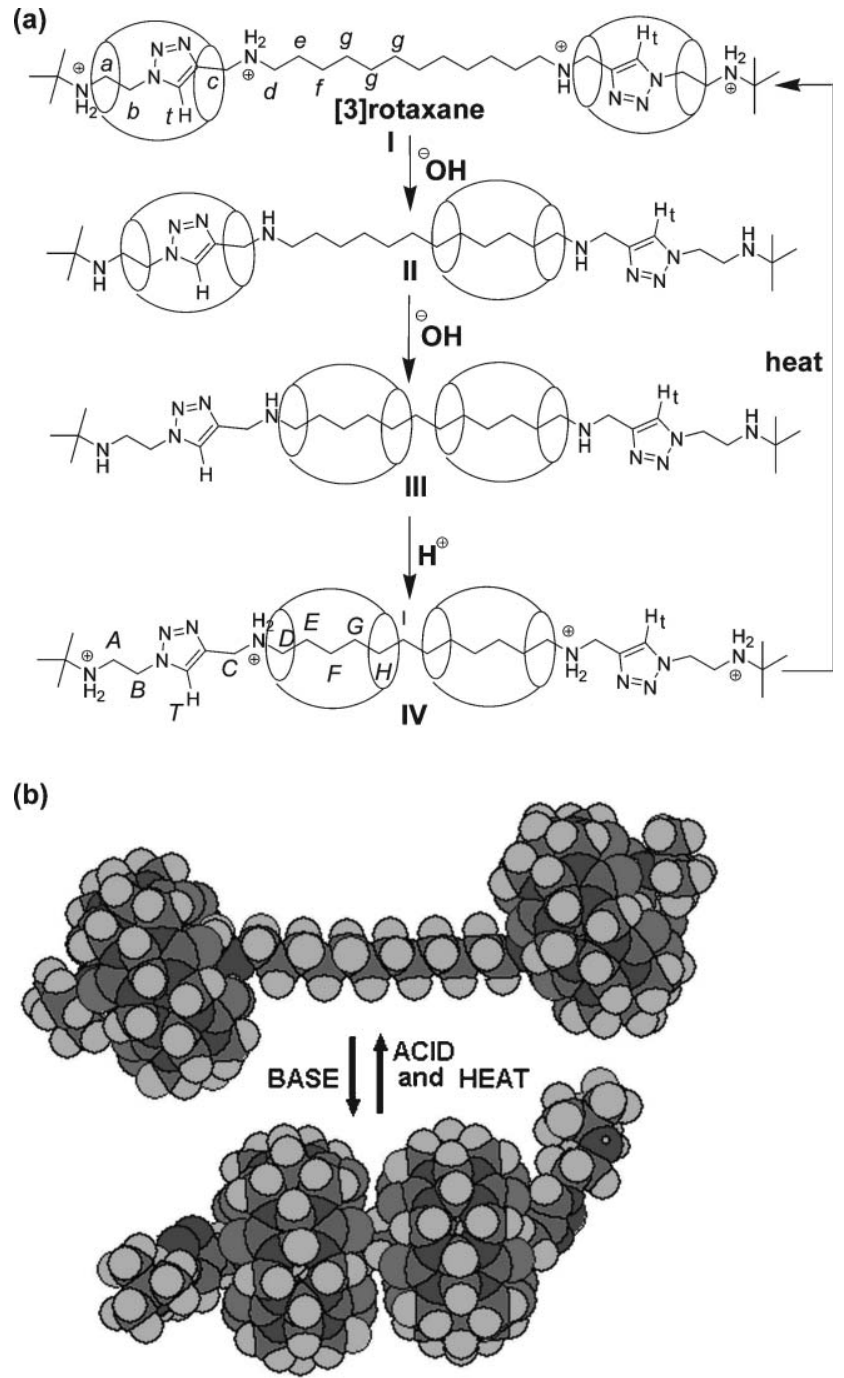

Fig. 2 (a) The chemical switching of CB6-based [3] rotaxane and its cycle of contraction and extension in solution (water) (in the drawings, the counter ion chlorides were omitted for the clarity). (b) Space filling models of [3]rotaxane in states I and III.

dumbbell of [3]rotaxane with one CB6 and the dumbbell with one CB6 and two potassium ions, respectively. The main peak at $\mathrm{m} / \mathrm{z}$ 2556 corresponds to the molecular ion of [3]rotaxane.

Fig. 2(a) illustrates the possible reversible switching processes of [3]rotaxane. In [3] rotaxane at low $\mathrm{pH}$ (state I), CB6 rings have a greater affinity for the diaminotriazole unit than for the diaminododecamethylene site. The interaction between rings and the diaminotriazole is mainly ion-dipole interactions between carbonyl groups of $\mathrm{CB} 6$ 's portals and the $-\mathrm{NH}_{2}{ }^{+}$- ions adjacent to the dodecyl spacer, and to the tert-butyl group. However, since the cavity of CB6 is hydrophobic, it is possible to force CB6s to move over the hydrophobic part of the molecule, the dodecamethylene spacer, if the ion-dipole interaction is disrupted by a base. The resulting complex is stabilized by the hydrophobic effect and by $\mathrm{H}$-bonding between the $-\mathrm{NH}$ adjacent to the dodecyl spacer, and the oxygen of the carbonyl groups (state III).

In order to investigate the acid-base switching of CB6s in [3] rotaxane, the solution of [3] rotaxane in $\mathrm{D}_{2} \mathrm{O}$ was treated with varying equivalents of base $(\mathrm{NaOH})$ and acid $(\mathrm{HCl})$; approx. 5 min later after each addition, and ${ }^{1} \mathrm{H}$ NMR spectra were recorded. The spectrum in Fig. 3(a) is that before the addition of any base or acid to the solution of [3]rotaxane. This is state I, as confirmed by the indicative signal at $6.5 \mathrm{ppm}$ due to encapsulated triazole proton. ${ }^{10 a}$

The addition of 1 equivalent of $\mathrm{NaOH}$ to the solution of [3]rotaxane in $\mathrm{D}_{2} \mathrm{O}$ caused a minute percentage of CB6s to move to the dodecyl part (Fig. 3(b)). A very small peak appeared due to unencapsulated triazole proton at $8.3 \mathrm{ppm}$; some new signals were also observed around $1.0 \mathrm{ppm}$ for the protons of the encapsulated methylene of the dodecyl spacer and the protons of tert-butyl. When 2 equivalents of base were added (spectrum not shown), significant changes were observed in the ${ }^{1} \mathrm{H}$ NMR spectrum, which revealed a signal at 6.5 for the encapsulated triazole proton $t$ and three signals for the unencapsulated triazole proton $\boldsymbol{T}$ at 7.9, 8.3 and 8.4 with the integral intensity ratio of $100: 15: 54: 16$, respectively. The appearance of three different signals due to unencapsulated triazole proton indicates the presence of more than one switching state of [3]rotaxane because of the movement of CB6 rings. Moreover, the size of peaks at 0.3 and $0.6 \mathrm{ppm}$ corresponding to the encapsulated methylene protons $\boldsymbol{F}$ and $\boldsymbol{E}, \boldsymbol{G}$ increased significantly. The addition of 3 equivalents of $\mathrm{NaOH}$ (Fig. 3(c)) further caused an increase in the size of these peaks. The signal at 7.9 ppm almost faded away, but the intensity of signals at 8.3 and $8.4 \mathrm{ppm}$ increased, while the intensity of the encapsulated triazole proton signal diminished. More significantly the intensity of the peak at $1.0 \mathrm{ppm}$ due to protons of tert-butyl increased, whereas the intensity of the peak at $1.5 \mathrm{ppm}$ decreased, thus indicating clearly that CB6s are not in close proximity to the tertbutyl group and thereby are upfield shifted. The addition of 5 equivalents of $\mathrm{NaOH}$ (Fig. 3(d)) triggered both $\mathrm{CBs}$ to shuttle over the dodecyl spacer, even though this state is thought to be less favourable because of the steric hindrance. Nevertheless, this spectrum clearly confirms the state III.

The peak corresponding to the encapsulated triazole proton at $6.5 \mathrm{ppm}$ almost completely disappeared and the two signals due to unencapsulated triazole protons emerged as a single signal at $8.4 \mathrm{ppm}$. Additionally, the signal at $1.5 \mathrm{ppm}$ corresponding to tertbutyl protons completely shifted downfield and was observed as a singlet at $1.0 \mathrm{ppm}$. From the space filling molecular model (Fig. 2(b)), it is clear that the dodecamethylene spacer is long enough to accommodate two CB6s; the driving force for the interaction between the alkyl spacer and the cavity of CB6 is mainly hydrophobic as well as $\mathrm{H}$-bonding between carbonyl oxygens of portals and - $\mathrm{NH}-$ adjacent to the dodecyl spacer. Furthermore, the interaction between carbonyl oxygens and the triazole ring proton, which extends towards to carbonyl portal for an efficient interaction, probably also contributes to this stability. The evidence for the latter interaction comes from downfield shift of the unencapsulated triazole proton peak from 7.9 to $8.4 \mathrm{ppm}$.

The addition of excess $\mathrm{HCl}$, produced some minor changes (spectrum not shown). For example, the signal due to tert-butyl protons shifted downfield by approx. $0.15 \mathrm{ppm}$ indicating the protonation of adjacent amine groups.

However, CB6s remained residing on the dodecyl spacer. Probably in this state (state IV), amines which are adjacent to the dodecamethylene spacer are protonated and the interactions are now both hydrophobic and ion-dipole; the activation energy would be high in order to allow CB6s to shuttle over their initial location. However, heating of the solution for $3 \mathrm{~min}$ at $60^{\circ} \mathrm{C}$ and 


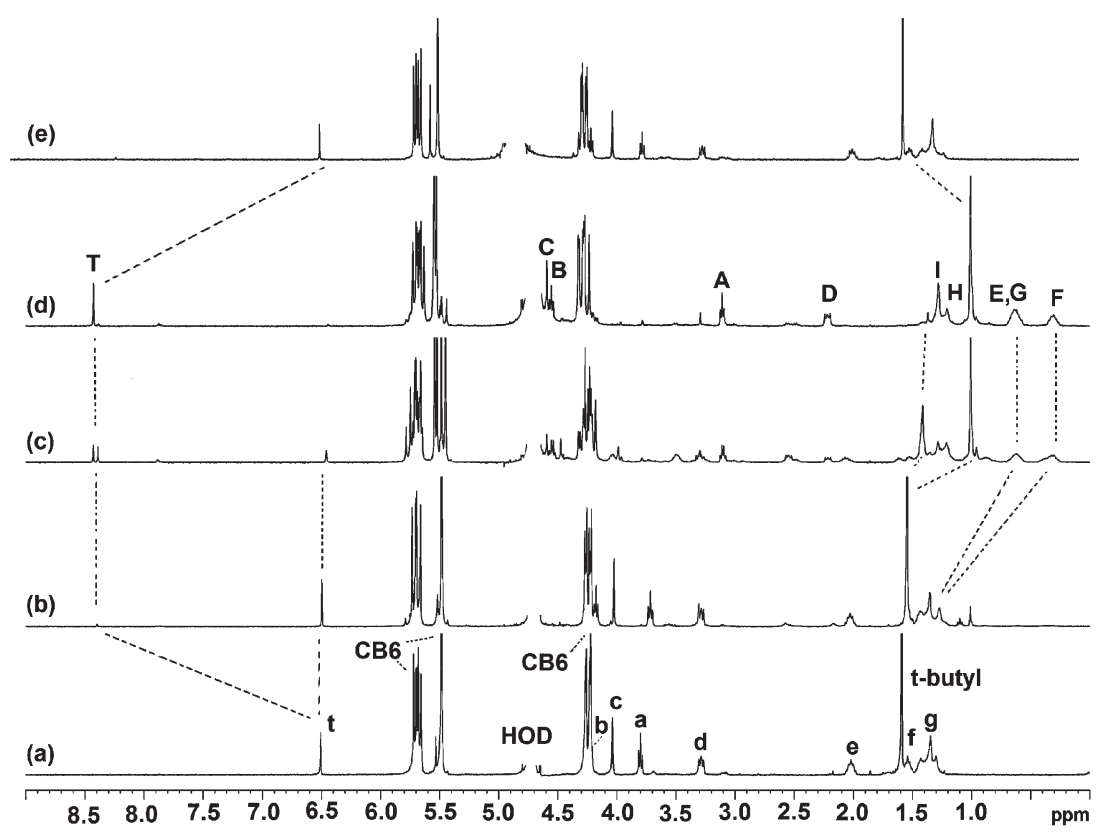

Fig. $3{ }^{1} \mathrm{H}$ NMR $\left(400 \mathrm{MHz}, \mathrm{D}_{2} \mathrm{O}, 25^{\circ} \mathrm{C}\right)$ spectra of; before the addition of base or acid (a) state I, after the addition of (b) 1 equiv. of $\mathrm{NaOH}$, (c) 3 equiv. of $\mathrm{NaOH}$, (d) 5 equiv. of $\mathrm{NaOH}$, (e) after addition of excess $\mathrm{HCl}$ and heating the solution to $60{ }^{\circ} \mathrm{C}$ for 3 min and cooling to rt.

then cooling to room temperature facilitated CB6s to shuttle to their thermodynamically more stable state which is state I. The space filling molecular models (Fig. 2(b)) show the state I and state III of [3]rotaxane.

In conclusion, we have reported a straightforward and highyield preparation of a bistable [3] rotaxane via CB6-catalyzed 1,3dipolar cycloaddition reaction. We also demonstrated that this rotaxane behaves as a molecular switch by exhibiting conformational changes via the movement of rings in response to the stimulation of base, acid and heat. This simply designed molecule has great potential for use as a molecular device in nanotechnological applications. Currently we are working towards immobilizing this rotaxane on surfaces in order to allow it to mimic the behavior of artificial muscles.

This research was supported by the Scientific and Technical Research Council of Turkey (TUBITAK, Grant No: MAG 105M027 and 105M094).

\section{Notes and references}

1 (a) Molecular Catenanes, Rotaxanes, and Knots, ed. J.-P. Sauvage and C. O. Dietrich-Buchecker, Wiley-VCH, Weinheim, 1999; (b) On molecular machine and motors: Special issue: ; J. F. Stoddart (ed.), Acc. Chem. Res., 2001, 6.

2 (a) S. A. Nepogodiev and J. F. Stoddart, Chem. Rev., 1998, 98, 1959; (b) J. D. Badjic, V. Balzani, A. Credi, S. Silvi and J. F. Stoddart, Science, 2004, 303, 1847; (c) V. Balzani, A. Credi, F. M. Raymo and J. F. Stoddart, Angew. Chem., Int. Ed., 2000, 39, 334; (d) A. G. Cheetham, M. G. Hutchings, T. D. W. Claridge and H. L. Anderson, Angew. Chem., Int. Ed., 2006, 45, 1596; (e) D. S. Marlin, D. A. Leigh and A. M. Z. Slawin, Angew. Chem., Int. Ed., 2006, 45, 77.
3 Y. Liu, A. F. Flood, P. A. Bonvallet, S. A. Vignon, B. H. Northrop, H.-R. Tseng, J. O. Jeppesen, T. J. Huang, B. Brough, M. Baller, S. Magonov, S. D. Solares, W. A. Goddard, C.-M. Ho and J. F. Stoddart, J. Am. Chem. Soc., 2005, 127, 9745.

4 M. C. Jimenez, C. D. Buchecker and J.-P. Sauvage, Angew. Chem., Int. Ed., 2000, 39, 3254

5 (a) M. C. Jimenez-Molero, C. D. Buchecker and J.-P. Sauvage, Chem. Commun., 2003, 1613; (b) S. Bonnet, J.-P. Collin, M. Koizumi, P. Moban and J.-P. Sauvage, Adv. Mater., 2006, 18, 1239.

6 W. L. Mock, in Comprehensive Supramolecular Chemistry, ed. F. Vogtle, Pergamon, Oxford, 1996, vol. 2, p. 477.

7 (a) K. Kim, Chem. Soc. Rev., 2002, 31, 96; (b) J. Kim, I.-S. Jung, S.-Y. Kim, E. Lee, J.-K. Kang, S. Sakamoto, K. Yamaguchi and K. Kim, J. Am. Chem. Soc., 2000, 122, 540.

8 J. Lagona, P. Mukhopadhyay, S. Chakrabarti and L. Isaacs, Angew. Chem., Int. Ed., 2005, 44, 4844.

9 (a) W. L. Mock and N.-Y. Shih, J. Org. Chem., 1986, 51, 4440; (b) W. L. Mock and N.-Y. Shih, J. Am. Chem. Soc., 1988, 110, 4706; (c) W. L. Mock, Top. Curr. Chem., 1995, 175, 1.

10 (a) D. Tuncel and J. H. G. Steinke, Chem. Commun., 1999, 1509; (b) D. Tuncel and J. H. G. Steinke, Chem. Commun., 2001, 253; (c) D. Tuncel and J. H. G. Steinke, Chem. Commun., 2002, 496; (d) D. Tuncel and J. H. G. Steinke, Macromolecules, 2004, 37, 288.

11 D. Tuncel, H. B. Tiftik and B. Salih, J. Mater. Chem., 2006, 16, 3291.

12 D. Tuncel, N. Cindir and Ü. Koldemir, J. Inclusion Phenom. Macrocycl. Chem., 2006, 55, 373.

13 (a) W. L. Mock and J. Pierpont, J. Chem. Soc., Chem. Commun., 1990, 1509; (b) S. I. Jun, J. W. Lee, S. Sakamoto, K. Yamaguchi and K. Kim, Tetrahedron Lett., 2000, 41, 471; (c) J. W. Lee, K. Kim and K. Kim, Chem. Commun., 2001, 1042; (d) K. Kim, W. S. Jeon, J.-K. Kang, J. W. Lee, S. Y. Jon, T. Kim and K. Kim, Angew. Chem., Int. Ed., 2003, 42, 2293; (e) J. W. Lee, K. Kim, S. W. Choi, Y. H. Ko, S. Sakamoto, K. Yamaguchi and K. Kim, Chem. Commun., 2002, 2692; (f) Y. J. Jeon, P. K. Bharadwaj, S. W. Choi, J. W. Lee and K. Kim, Angew. Chem., Int. Ed., 2002, 41, 4474; (g) V. Sindelar, S. Silvi and A. E. Kaifer, Chem. Commun., 2006, 2185. 